\title{
LAV@HAZARD: a web-GIS interface for volcanic hazard assessment
}

\author{
Annamaria Vicari ${ }^{1,{ }^{\star}}$, Giuseppe Bilotta ${ }^{1,2}$, Sergio Bonfiglio ${ }^{1,2}$, Annalisa Cappello ${ }^{1,2}$, Gaetana Ganci ${ }^{1}$, \\ Alexis Hérault ${ }^{3}$, Eugenio Rustico ${ }^{1,2}$, Giovanni Gallo ${ }^{2}$, Ciro Del Negro ${ }^{1}$
}

\author{
${ }^{1}$ Istituto Nazionale di Geofisica e Vulcanologia, Sezione di Catania, Osservatorio Etneo, Catania, Italy \\ ${ }^{2}$ Università di Catania, Dipartimento di Matematica e Informatica, Catania, Italy \\ ${ }^{3}$ Conservatoire des Arts et Métiers, Département Ingénierie Mathématique, Paris, France
}

\author{
Article history \\ Received November 29, 2010; accepted May 31, 2011. \\ Subject classification: \\ Volcanic hazard, Web-GIS, Decision support system.
}

\begin{abstract}
Satellite data, radiative power of hot spots as measured with remote sensing, historical records, on site geological surveys, digital elevation model data, and simulation results together provide a massive data source to investigate the behavior of active volcanoes like Mount Etna (Sicily, Italy) over recent times. The integration of these heterogeneous data into a coherent visualization framework is important for their practical exploitation. It is crucial to fill in the gap between experimental and numerical data, and the direct human perception of their meaning. Indeed, the people in charge of safety planning of an area need to be able to quickly assess hazards and other relevant issues even during critical situations. With this in mind, we developed LAV@HAZARD, a web-based geographic information system that provides an interface for the collection of all of the products coming from the LAVA project research activities. LAV@HAZARD is based on Google Maps application programming interface, a choice motivated by its ease of use and the user-friendly interactive environment it provides. In particular, the web structure consists of four modules for satellite applications (time-space evolution of hot spots, radiant flux and effusion rate), hazard map visualization, a database of ca. 30,000 lava-flow simulations, and real-time scenario forecasting by MAGFLOW on Compute Unified Device Architecture.
\end{abstract}

\section{Introduction}

Mount Etna is one of the most active volcanoes in the world. It has shown almost continuous activity throughout historical times, which has covered an area of more than $1,000 \mathrm{~km}^{2}$. In recent years population growth and urban expansion have greatly increased the impact of volcanic events, making correct land-use planning a fundamental requirement for the minimizing of both economic losses and damage to property.

During an effusive eruption, a massive amount of heterogeneous data become available. All of these data are difficult to manage, especially during the early phases of an emergency. For this reason, we developed a platform, named
LAV@HAZARD, that can integrate information coming from different sources, using geographic information systems (GIS), remote-sensing processing, and physical modeling.

GIS is a tool that integrates, stores, edits, analyzes, shares and displays geographic data, for informed decision making. In particular, web-based GIS (web-GIS) applications facilitate the elaboration of geographic information through web browsers that use various forms of web-based application programming interfaces. The manipulation of data extends from a simple overlay of different maps for the identification of specific areas, to a more complicated use of numerical models for simulating the dynamics of volcanic phenomena. GIS has already been applied to volcanic hazard assessment and risk management [e.g. Pareschi et al. 2000, Groppelli and Norini 2005, Felpeto et al. 2007].

Remote-sensing processing is a powerful and reliable instrument for volcanic monitoring, both in terms of hot-spot detection and quantitative estimations of lava effusion rates [e.g. Rothery et al. 1988, Pieri et al. 1990, Harris et al. 1997].

Finally, physical modeling represents a fundamental instrument for the forecasting of the spatial and temporal evolution of volcanic lava flows. In particular, the MAGFLOW cellular automaton model has been applied to the reproduction of recent eruptions, with encouraging results [Vicari et al. 2007, Del Negro et al. 2008], as well as to evaluate hazard mitigation actions [Scifoni et al. 2010].

LAV@HAZARD is a dynamic web-GIS that represents a first effort to link GIS with remote-sensing processing and physical modeling [Felpeto et al. 2007]. This data visualization system is built on the popular Google Maps service, a choice that was motivated by the ease of use of its application programming interface and the user-friendly interactive environment it provides. The javascript language used in the development of the web interface makes extensive use of jQuery, a javascript library that simplifies 
HTML document traversing, event handling and animating, and Ajax interactions. The creation of all of the charts is accomplished through Flot, a javascript plotting library for jQuery that produces interactive graphical plots of arbitrary datasets on-the-fly client-side.

In this study, we describe the potentialities of LAV@HAZARD, as specifically planned for volcanic hazard assessment and to provide suitable tools during emergencies at Mount Etna volcano. LAV@HAZARD consists of four modules, for: satellite applications (time-space evolution of hot spots, radiant flux, effusion rate, etc.) [Tramutoli 2007, Hirn et al. 2008, Ganci et al. 2009]; lava-flow hazard-map visualization; a database of lava-flow simulations according to the MAGFLOW model [Vicari et al. 2007, Del Negro et al. 2008]; and real-time scenario forecasting by MAGFLOW on Compute Unified Device Architecture (CUDA) architecture [Bilotta et al. 2011a].

\section{The satellite module}

Over the last 20 years, multispectral infrared (MIR) observations have shown that analysis of satellite images is a powerful and reliable instrument for volcanic monitoring. The data provided by the Landsat spacecraft (of the National Aeronautics and Space Administration) have high spatial resolution $(30 \times 120 \mathrm{~m}$ pixels $)$ and low temporal resolution (16 days) and have been used in the past for thermal analysis of active lava flows [Oppenheimer 1991], lava domes [Francis and McAllister 1986, Kaneko et al. 2002], lava lakes [Harris et al. 1999] and fumarole fields [Harris and Stevenson 1997]. High spatial resolution images can provide useful information for detailed characterization of the thermal properties of a volcano. However, images with lower spatial but high temporal resolution from the advanced very-highresolution radiometer (AVHRR), the moderate resolution imaging spectrometer (MODIS) and the spinning enhanced visible and infrared imager (SEVIRI) have been shown to be suitable for continuous monitoring of volcanic activity [Harris et al. 1997, Wright et al. 2001, Hirn et al. 2008]. AVHRR provides data at least four times a day for any subaerial volcano, with a spatial resolution of $c a .1 \mathrm{~km}^{2}$. MODIS offers an additional dataset to look at volcanic hot spots, with the advantage of using up to 10 wavebands suitable for hot-spot detection. SEVIRI represents a unique opportunity as volcanic eruption detection system in realtime by providing images at 15 -min intervals, despite to its spatial resolution, which is $c a .15 \mathrm{~km}^{2}$ over Mount Etna.

Despite the huge amount of satellite data, it is very difficult to provide real-time elaboration of these data during a crisis. To try to respond to this objective, tools for real-time detection of volcano hot spots, radiative power evaluation, and effusion-rate estimations have been developed (Figure 1).

A database of satellite data has been linked to data coming from the elaboration of different algorithms that can ingest multispectral data from sensors aboard meteorological satellites, such as AVHRR, MODIS and SEVIRI.

As for hotspot detection, the robust satellite techniques approach [Tramutoli 2007] was optimized by a long-term time-domain analysis that was performed on several satellite records, which covered the Mount Etna area, and applied to both AVHRR and MODIS data. The satellite data were analyzed by the computation of a local variation index, in a MIR spectral band, to identify hot spots.

Other automatic systems that can not only provide hotspot detection, but can also allow the estimation of radiative power and lava-flow effusion rates were optimized by MyMET [Hirn et al 2008] and HotSat [Ganci et. al. 2009]. Mymet applied to SEVIRI data accounts for three channels (MIR to TIR) for hot-spot detection, and four channels (SWIR to TIR) for radiant flux computation, with either the dual-band or the three-band methods. HotSat is a new contextual algorithm that elaborates both MODIS and SEVIRI data for thermal anomalies, by exploiting the different features of the two sensors: the high frequency of SEVIRI acquisition, and the spatial precision of MODIS data. To derive radiant flux, HotSat applies the MIR radiance method introduced by Wooster et al. [2003]. All of the pixels classified as hot are geolocated and visualized on the map. A data range is selectable by users, and statistical analysis is performed on data. Other products are available, depending on user choices, e.g. radiant flux and effusion rates [Hérault et al. 2009, Vicari et al. 2009].

Once for every time interval, the sensor to be considered as the data source and the interpolation algorithm are selected, and two charts are graphically presented: one that shows the number of hotspots, and the other that shows the evolution of the radiative power on the primary axis and the effusion rate on the secondary axis. By clicking on whatever point in the two plots, the corresponding hotspot pixels are shown on the map. Moreover, each hot pixel is colored according to the intensity of the radiative power (as for the HotSat and MyMet products) or based on the values of the absolutely local index of change of the environment (ALICE) index (as for robust satellite techniques), and the exact value is shown by clicking on the colored pixel itself. By default, the hotspots of the last satellite image in the time range are shown over the map.

The thermal methodology for obtaining effusion rates is based on a study of Pieri and Baloga [1986]. The corresponding total amount of lava volume estimated can be visualized by selecting a time interval and an algorithm among Hotsat MODIS, Hotsat SEVIRI and MyMET SEVIRI.

This modules offers great potential due to the userfriendly interface that was developed for analysis of satellite images coming from different sensors. Moreover, it represents a very useful instrument for continuous monitoring to detect changes in volcanic activity. 

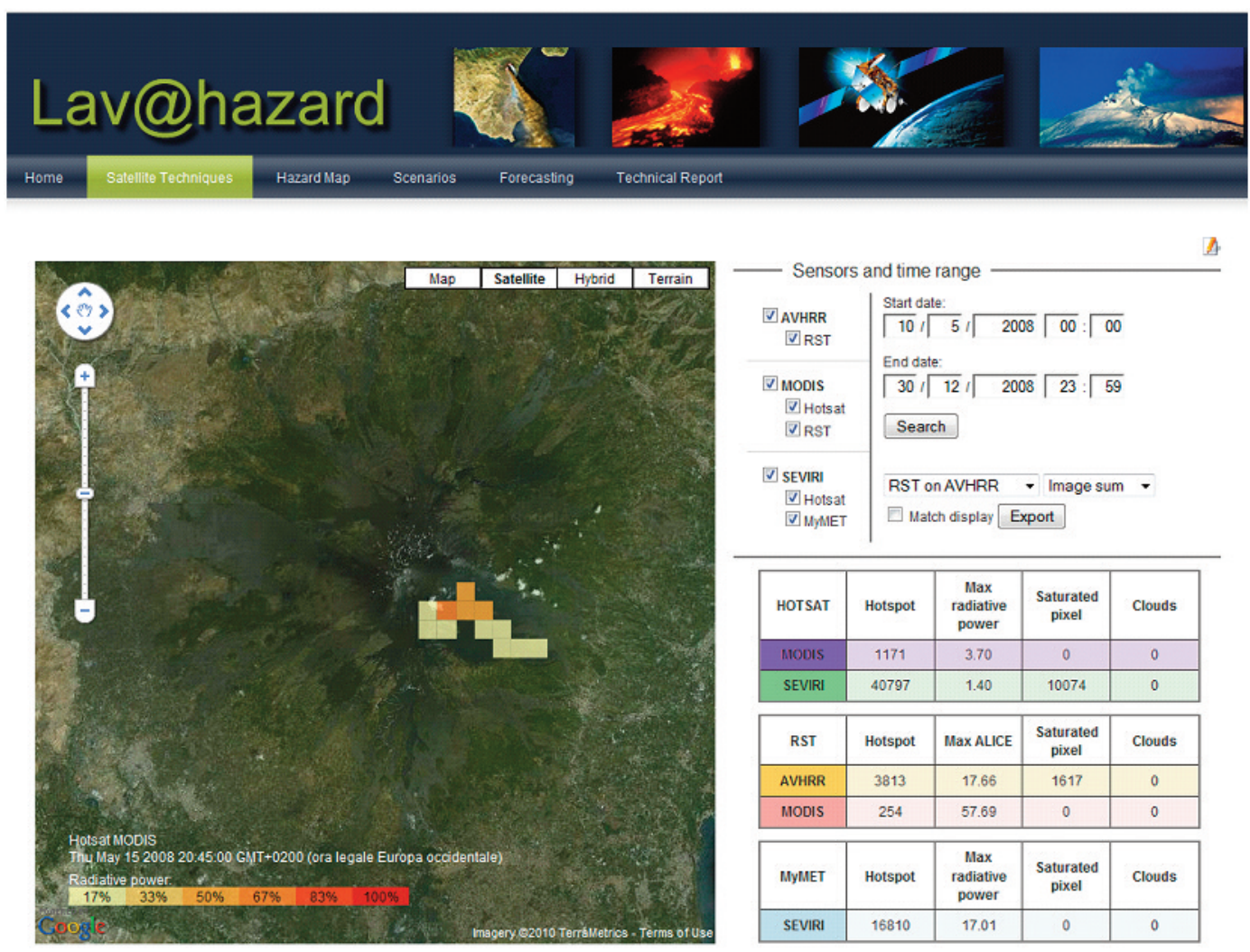

\begin{tabular}{|c|c|c|c|c|}
\hline HOTSAT & Hotspot & $\begin{array}{c}\text { Max } \\
\text { radiative } \\
\text { power }\end{array}$ & $\begin{array}{c}\text { Saturated } \\
\text { pixel }\end{array}$ & Clouds \\
\hline MODIS & 1171 & 3.70 & 0 & 0 \\
\hline SEVIRI & 40797 & 1.40 & 10074 & 0 \\
\hline RST & Hotspot & Max ALICE & $\begin{array}{c}\text { Saturated } \\
\text { pixel }\end{array}$ & Clouds \\
\hline AVHRR & 3813 & 17.66 & 1617 & 0 \\
\hline MODIS & 254 & 57.69 & 0 & 0 \\
\hline MYMET & Hotspot & $\begin{array}{c}\text { Max } \\
\text { radiative } \\
\text { power }\end{array}$ & $\begin{array}{c}\text { Saturated } \\
\text { pixel }\end{array}$ & Clouds \\
\hline SEVIRI & 16810 & 17.01 & 0 & 0 \\
\hline
\end{tabular}
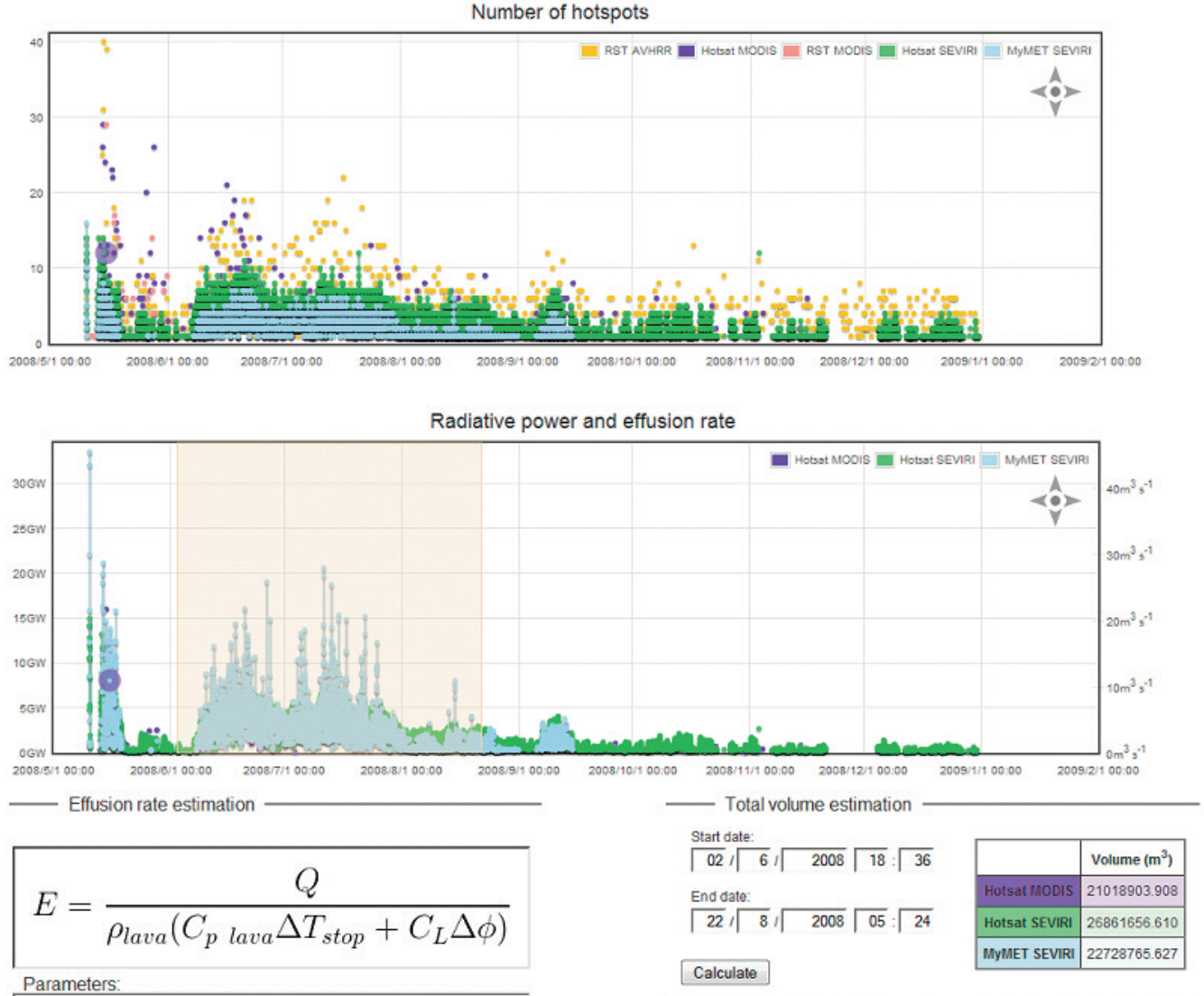

\begin{tabular}{|c|c|c|c|c|c|}
\hline Parameters & & & & & \\
\hline$\rho_{\text {lava }}$ & 2600 & $C_{\text {plava }}$ & 1150 & $\Delta \phi \Gamma$ & 0.22 \\
\hline$\Delta T_{\text {stop }}$ & 180 & $C_{L}$ & $3.5 \mathrm{e}+05$ & & Recalculate \\
\hline
\end{tabular}

Figure 1. Screenshot of the satellite module. Top left: A HotSat elaboration of a MODIS image of May 15, 2008, at 20:45 UTC. The colors of the pixels on the Google map represent different values of radiant flux. Top right: Statistical analysis for the selected period. Bottom: Number of hotspots detected by the robust satellite techniques, MyMet and HotSat, and the correspondent radiative power. Yellow transparent window, the selected period for volume computation starting from the estimated lava-effusion rate. The parameters for the computation of the lava-effusion rate can be changed, with the recalculation of the emitted volume in the selected temporal window. 


\section{The scenarios module}

The aim of the scenario module (Figure 2 ) is to visualize the simulations $(\mathrm{ca} .30,000)$ used for the development of the lava-flow hazard map at Mount Etna volcano.

Lava-flow inundation areas were simulated using the MAGFLOW code, which has been extensively used in lavaflow hazard applications at Mount Etna. The MAGFLOW model is based on a cellular automaton structure, in which the states of the cells are the thickness of lava and the quantity of heat. The states of the cells are synchronously updated according to local rules that depend on the values of the cell and the values of neighbors within a certain proximity. The evolution function of MAGFLOW is a steadystate solution of Navier-Stokes equations for the motion of a Bingham fluid on an inclined plane that is subject to pressure force, in which the conservation of mass is guaranteed both locally and globally [Vicari et al. 2007]. Rheological properties are modeled using a variable viscosity relationship, as described by Giordano and Dingwell [2003], and parameterized in terms of temperature and water content [Del Negro et al. 2008].

An important parameter to run the MAGFLOW simulator is the lava-effusion rate. Starting from statistical analysis of the last 400 years of activity at Mount Etna, the

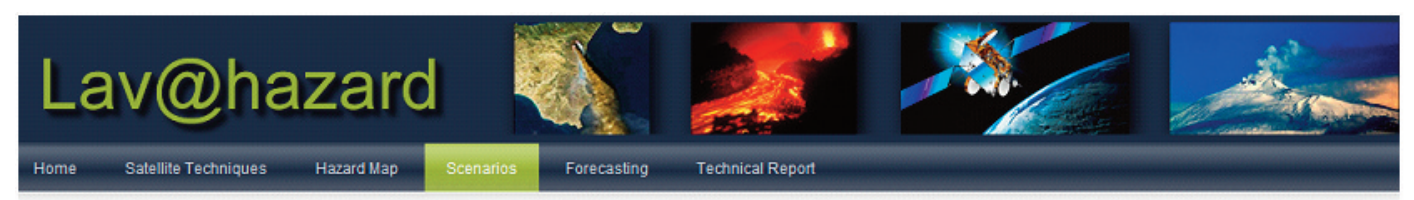

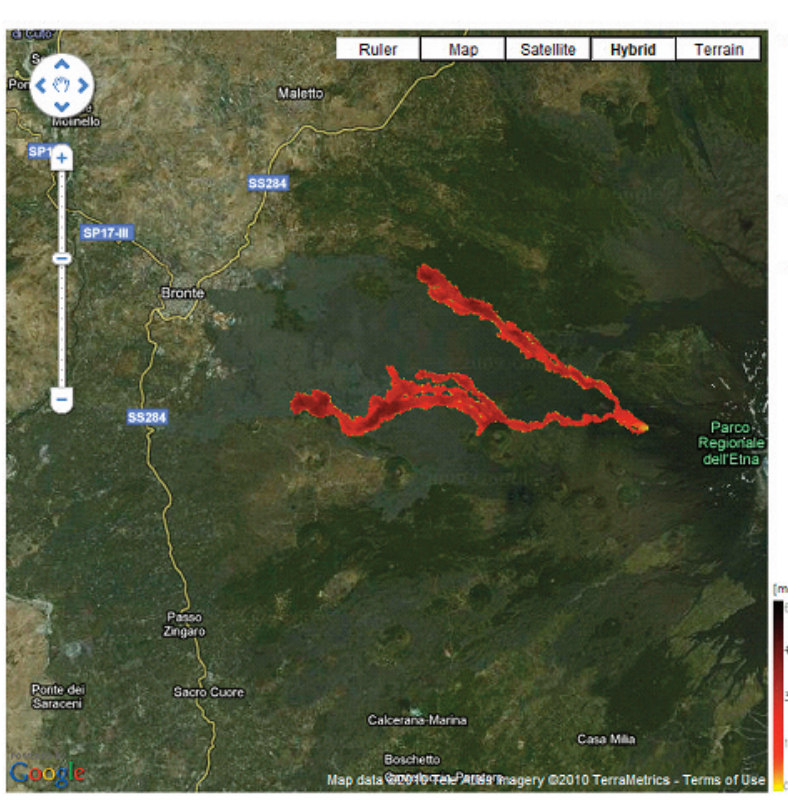

Giorno: 30
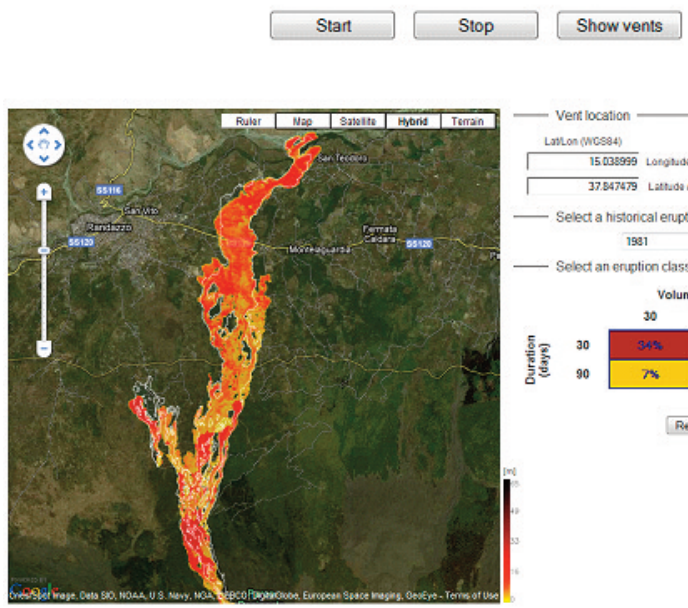

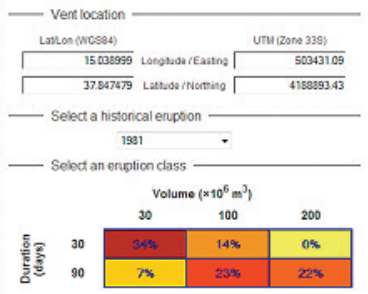

Resert.

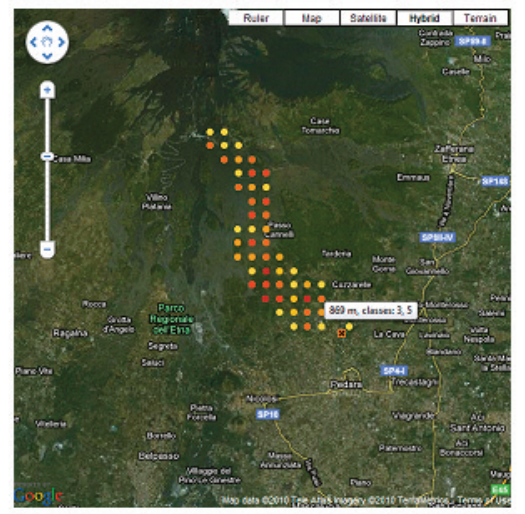

Figure 2. Screenshot of the scenarios module. Top left: Lava flow simulation extracted from the database. The colors of the pixels on the Google map represent different thicknesses of the lava flow. Top right: the main vent, the eruptive class, and the curve of the effusion rate. Bottom: The 1981 Etna eruption as simulated by MAGFLOW superimposed on the observed lava flow field (white contour), with an example of the vents obtained by inverting the simulation. 
short-medium term and a long term were set to 30 days and 90 days of simulation, respectively, and 30, 100 and $200 \times 10^{6}$ $\mathrm{m}^{3}$ were fixed as the erupted lava volumes. Combining these values we obtained six possible functions that represent the variation of the lava-flux rate in relation to the time of an eruption. The curves have been considered as bell shaped [Vicari et al. 2007], where the eruption starts from a null value of the laval-flux rate, reaches its peak after $25 \%$ of the entire time of simulation, and then gradually decreases until the end of the eruption.

For every vent of the grid. six simulations were carried out, with each one characterized by its own effusion rate and duration. To avoid an ideal trend for all of the simulations, a small random perturbation (within an interval of $[-1 / 6$, $+1 / 6]$ of the value considered) was performed on the effusion-rate curves for each vent of the grid.

Choosing a main vent (by clicking on the map or by directly inserting the Cartesian coordinates) and an event class, the evolution of a stored simulation starts. The systems provides an alerts if the selected point does not fall within the grid of vents, and allows the user to stop and restart the simulation at any time.

The coordinates of the main vents for eruptions at Mount Etna that have occurred in the last 400 years, divided according to class, can be selected by the user and visualized on the map. Moreover, some historical eruptions simulated by MAGFLOW (Table 1) can be displayed on the map.

It is also possible to visualize all of the vents that belong to the simulation grid that produces eruptions that can invade a specific point, with the associated eruptive class and relative altitude (inversion of a simulation). These functionalities prove to be very useful during an eruption, to individuate emission areas that can generate threatening lava flows for a critical areas (e.g. inhabited zones, roads, hospitals, power plants, etc.).

\section{The hazard module}

The quantification of hazards is one of the main priorities of modern volcanology. A common approach is based on the identification of the most dangerous areas on the basis of the spatial and temporal distribution of past volcanic events.

The aim of this module is the visualization of the map that shows the long-term hazard related to lava invasion in Mount Etna [Cappello et al. 2010]. The basic idea is to determine the hazard zones through the identification of the emission regions with the highest probabilities of hosting eruptive vents, and by characterizing the event types for the numerical simulations, to compute an eruptive probability.

The computation of a vent-opening probability map (a susceptibility map) is based on the characterization of the zones with the highest probabilities of future eruptive vents opening, through the evaluation of both a spatial probability

\begin{tabular}{ccc}
\hline Eruption year & Onset & End \\
\hline $1634-1636$ & December 19, 1634 & June, 1636 \\
$1646-1647$ & November 20, 1646 & January 17, 1647 \\
1763 & June 18, 1763 & September 10, 1763 \\
1766 & April 27, 1766 & November 6, 1766 \\
1669 & March 11, 1669 & July 11, 1669 \\
$1792-1793$ & May 11, 1792 & May 25, 1793 \\
1809 & March 27, 1809 & April 9, 1809 \\
1865 & January 30, 1865 & June 28, 1865 \\
1874 & August 29, 1874 & August 31, 1874 \\
1879 & May 26, 1879 & June 7, 1879 \\
1886 & May 19, 1886 & June 7, 1886 \\
1892 & July 9, 1892 & December 29, 1892 \\
1981 & March 17, 1981 & March 23, 1981 \\
2001 & July 18, 2001 & August 9, 2001 \\
2006 & July 15, 2006 & July 24, 2006 \\
\hline
\end{tabular}

Table 1. The historical eruptions simulated by MAGFLOW.

density function (PDF) and a temporal recurrence rate [Martin et al. 2004, Marti and Felpeto 2010].

For estimation of the PDF, we applied a Gaussian kernel separately to eruptive fissures, dikes and faults. Different combinations of the PDFs can be visualized on the map by assigning a particular relevance value (weight) to each dataset. The activation probability for each point is evaluated using a Poisson distribution with a time interval of 50 years. For characterization of the expected eruptions, we performed a statistical analysis on the duration volumes of the effusive activity data for Mount Etna over the past 400 years [Proietti et al. 2011], from which we obtained six eruptive classes and evaluated the probability that one of the considered classes occurs for each point. The lava-flow inundation areas were simulated using the MAGFLOW code with the typical material properties of Etnean basaltic lava (Table 2). The basis for the numerical simulations was a digital elevation model of the volcano area that was updated to 2005 , represented as a $10 \mathrm{~m}$ cell grid and a vent grid spaced

\begin{tabular}{lcc}
\hline Parameter & Value & Unit \\
\hline Density of lava & 2600 & $\mathrm{~kg} \mathrm{~m}^{-3}$ \\
Specific heat & 1150 & $\mathrm{~J} \mathrm{~kg}^{-1} \mathrm{~K}^{-1}$ \\
Emissivity of lava & 0.9 & - \\
Temperature of solidification & 1143 & $\mathrm{~K}$ \\
Temperature of extrusion & 1360 & $\mathrm{~K}$ \\
\hline
\end{tabular}

Table 2. Typical parameters for Mount Etna lava flows. 
at the regular interval of $500 \mathrm{~m}$ [Gwinner et al. 2006]. The lava-flow hazard map was obtained by taking into account the information on both the lava-flow overlap and the defined probabilities of lava-flow occurrence.

The hazard module of LAV@HAZARD (Figure 3) collects the results obtained during the different phases of this methodology. The main volcanic structures of Mount Etna, as fissures, dikes and faults [Neri et al. 2011], can be visualized on the map, together with the resulting PDFs. To display a global map that shows all kinds of information, the user can select among the different combinations of weights for the PDFs.

The interface also allows for a specific area to be selected, and for the visualization of the hazard map obtained by activation of only the inner grid vents, assigning each of these the same activation and event probability. Here, the event probability represents the probability that one of the six eruptive classes occurs for every point of the grid. The resulting map is useful during the first phases of an emergency, when the lava flows on surface are not evident, with the availability of only the monitoring signals that indicate the possibility of the opening of eruptive fissures.

\section{The forecasting module}

Modeling and simulation of lava flows in real-time is of extreme importance for short-term hazard assessment in volcanic areas. An integrative estimate of the hazard can be obtained through physical models that simulate the evolution of volcanic phenomena and allow the estimation of the area affected by a volcanic event.

The MAGFLOW model was developed at the Istituto Nazionale di Geofisica e Vulcanologia (INGV), Catania
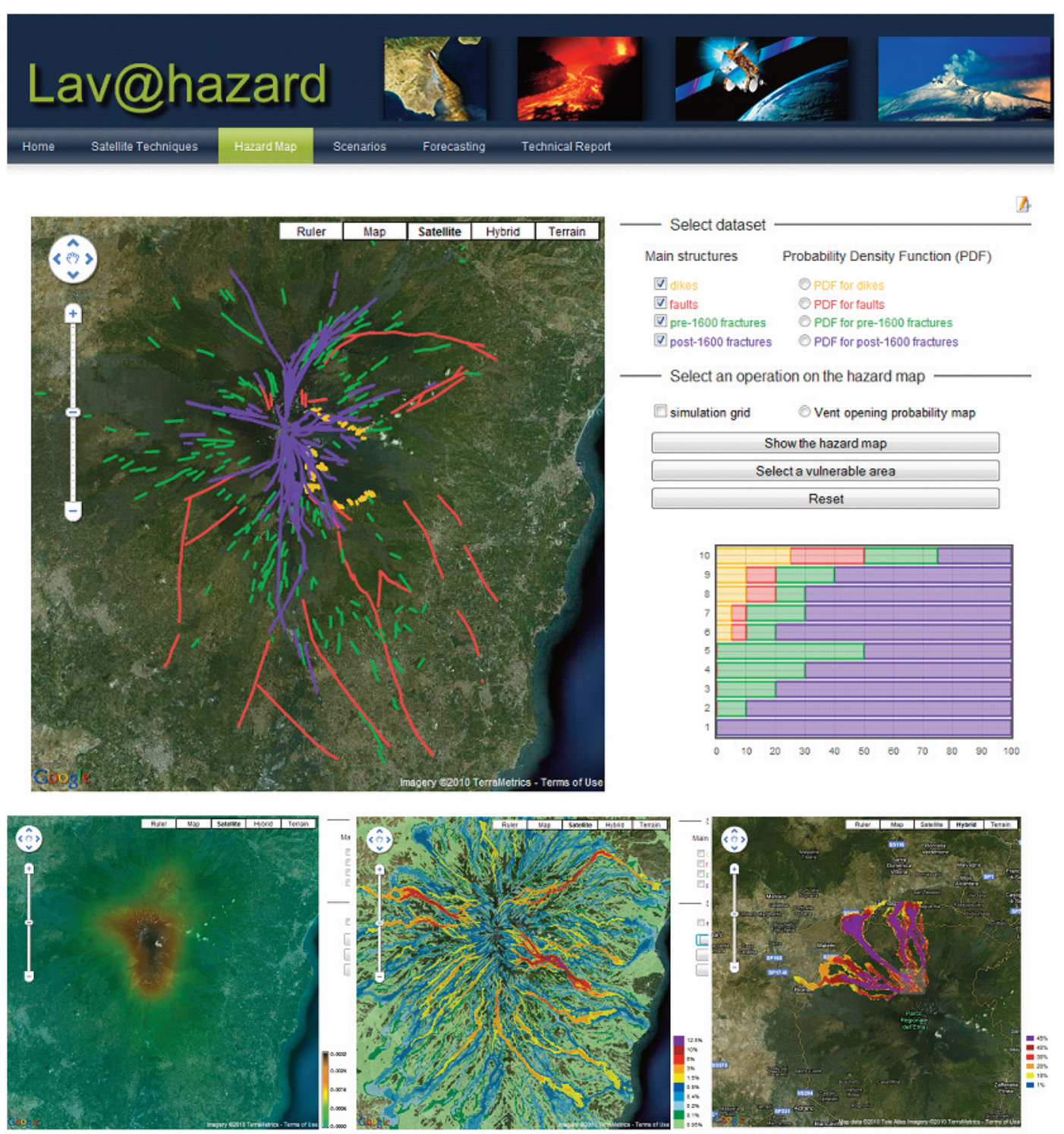

Figure 3. Screenshot of the hazard module. Top left: Main volcanic structures (dikes, fault and fissures) used for building the lava-flow invasion hazard map of Mount Etna, shown on the Google map. Top right: Table to select the final PDF as a combination of the different PDFs. Bottom: the final PDF selected, the long-term hazard map calculated with the previously selected PDF, and an example of the hazard map re-calculated only for a small area. The colors are associated with different levels of probability. 
Section, and it is one of the few cellular automata based on physical modeling of lava flows, which includes thermal effects, to describe the evolution of the system. It has been successfully used to reproduce past events with welldetermined characteristics, to predict lava flows in real-time during the Mount Etna 2004, 2006 and 2008 eruptions, and to evaluate the lava-flow invasion hazard in the presence of artificial barriers [Scifoni et al. 2010].

Although the original MAGFLOW implementation was intended for serial execution on standard CPUs, the cellular automaton paradigm has a very high degree of parallelism, which makes it suitable for implementation on parallel computing hardware. In particular, MAGFLOW has been implemented on graphic processing units, as they offer very high performance in parallel computing with a total cost of ownership that is significantly less than that of traditional computing clusters of equal performance.

Bilotta et al. [2011a] implemented the MAGFLOW model using CUDA, an architecture provided by NVIDIA for the deployment of their latest generations of graphic processing units as high-performance computing hardware.

The conversion of the serial CPU code leads to a $40 \times$ speed-up in execution on the latest generation of CUDA cards, with a negligible loss in precision. This means that on graphic processing units, MAGFLOW provides the result of a simulation that lasts seven days in a couple of minutes.

The forecasting module (Figure 4) allows immediate control of the MAGFLOW simulator on the CUDA architecture, to produce scenario forecasts in real-time as required by web applications. The user can select a vent location (by clicking on the map or by directly inserting the Cartesian coordinates), the duration of the simulated flow,
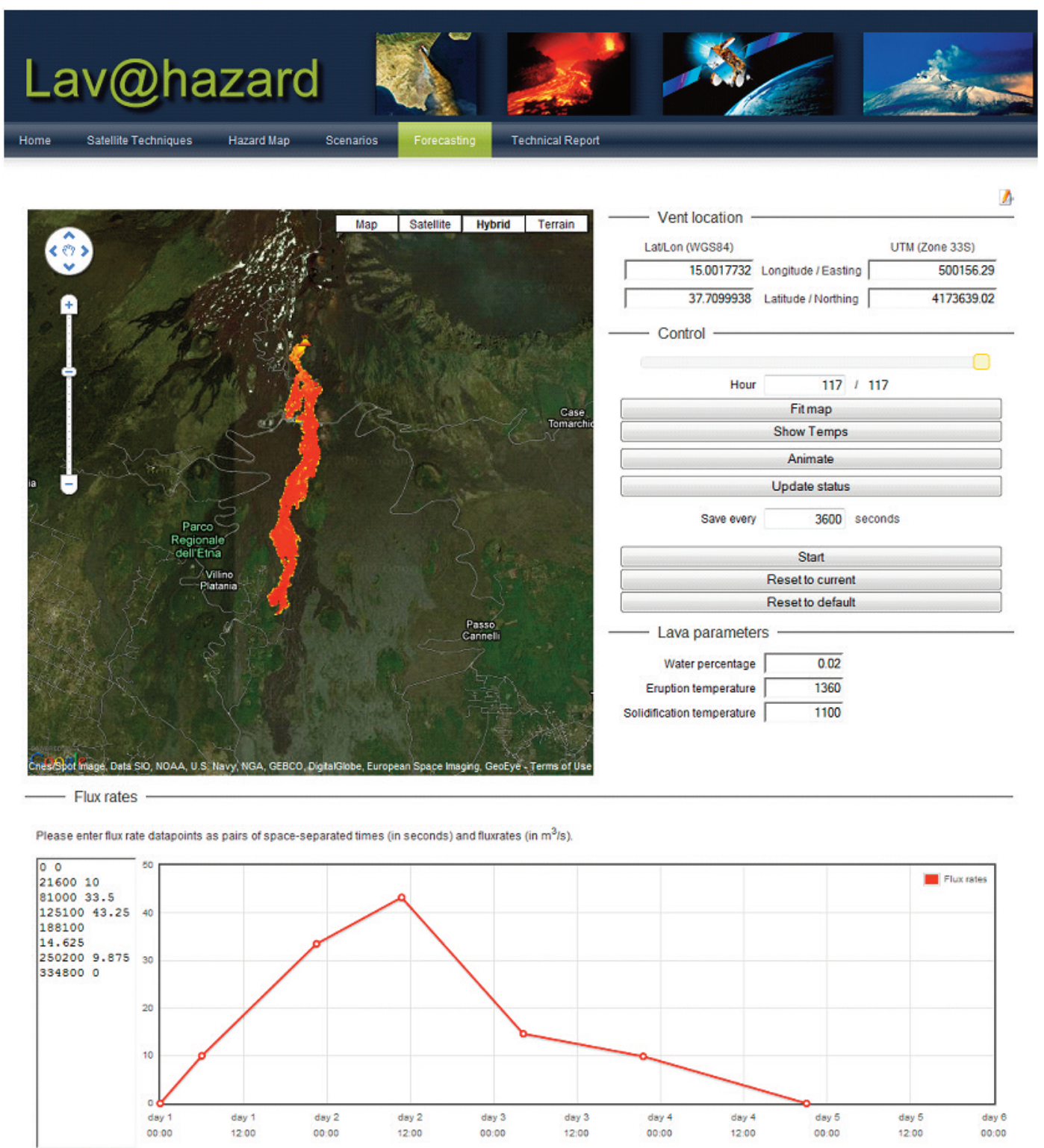

Figure 4. Screenshot of the forecasting module. Top left: real-time simulation performed by the MAGFLOW model on the CUDA architecture. Top right: The main parameters used for the simulation. Bottom: Curve of the effusion rates used for the simulation. The colors of the lava flow path are associated with different thicknesses or to the temperature of the lava flow. 
the timing for saving, the physical and rheological parameters necessary for the model, and the expected effusion rate.

Three parameters can be modified for the lava flow: the eruption temperature, the solidification temperature, and the water percentage, which determines the viscosity of the flow.

The expected effusion rate can be entered by specifying a list of data points as pairs of space-separated times (in s) and flux rates (in $\mathrm{m}^{3} / \mathrm{s}$ ). Otherwise the user can dynamically construct the effusion rate function by exploiting the chart available through Flot, a javascript plotting library for jQuery that furnishes interactive graphic plots of arbitrary datasets on-the-fly client-side.

Once these initial parameters are set, the user can remotely start the simulator and display the results as they become available.

\section{Conclusions}

An experimental system that can provide support for earth science experts, public safety experts and political managers during emergencies has been presented here. Its great value is the ability to integrate information coming from different sources all in one visual framework: satellite data, historical events, real-time simulations, etc.

Spaceborne remote sensing of high-temperature volcanic features offers an excellent opportunity to monitor the onset and development of new eruptive activity. Moreover, when a volcano erupts, investigations of the regions of high hazard in real-time is one of the most difficult problems to deal with. Accurate and robust physicalmathematical models are good tools for this purpose. These allow an estimation of the level of damage that might be caused by a volcanic eruption, and can predict the size and extent of lava flows. Numerical simulations allow the exploration of various eruption scenarios, and these can be used specifically to estimate the extent of the lava-inundation area, the time required for the lava flow to reach a particular point, and morphological changes that might result.

MAGFLOW was designed as a tool to simulate lava-flow behavior, with regard to real physical data obtained during an eruptive event. It is intended for use in emergency response situations during an eruption, to quickly forecast the lava-flow path over a time interval from the immediate future to long-time prediction.

All of this useful information has been gathered into LAV@HAZARD, a newly-developed information system that is dedicated to promote mitigation actions through its high degree of interactivity, its easily readable maps, and its fast way to explore alternative scenarios. These characteristics make our system a promising tool to assist decision makers both in their future planning and during emergencies.

Although the system is already quite mature, new developments are expected for the future. We are still working on the usability issues of its graphical user interface and experimenting with different graphical choices, to make its visual communication more intuitive. Another improvement will be provided by the use of real-time satellite data to drive numerical simulations of lava-flow paths and to produce a detailed chronology of lava-flow emplacement while an eruptive event is ongoing. Bilotta et al. [2011b] demonstrated that for the MAGFLOW simulator, the volumetric flux of lava from a vent (i.e. the lava-effusion rate) is the principal parameter that controls the final lava-flow dimensions. A further possible enhancement of LAV@HAZARD will be real-time elaboration of the satellite data, to estimate the effusion rate function to introduce as input information for prediction of the path of a lava flow. In this way, LAV@HAZARD looks set to become an effective tool for real-time monitoring and mitigation of volcanic hazard.

Acknowledgements. This study was performed with financial support from the V3-LAVA project (INGV-DPC 2007-2009 contract). The authors thank A. Felpeto, G. Norini and G. Groppelli for their helpful and constructive comments.

\section{References}

Bilotta, G., E. Rustico, A. Hérault, A. Vicari, G. Russo, C. Del Negro and G. Gallo (2011a). Porting and optimizing MAGFLOW on CUDA, Annals of Geophysics, 54 (5), 580-591 (this issue).

Bilotta, G., A. Cappello, A. Hérault, A. Vicari, G. Russo and C. Del Negro (2011b). Sensitivity analysis of the MAGFLOW cellular automaton model, Environ. Modell. Softw., submitted.

Cappello, A., A. Vicari and C. Del Negro (2011). Assessment and modeling of lava flow hazard on Mt Etna volcano, B. Geofis. Teor. Appl., 52 (2), 299-308.

Del Negro, C., L. Fortuna, A. Hérault and A. Vicari (2008). Simulations of the 2004 lava flow at Etna volcano by the MAGFLOW cellular automata model, B. Volcanol., 70, 805-812.

Felpeto, A., J. Martí and R. Ortiz (2007). Automatic GIS-based system for volcanic hazard assessment, J. Volcanol. Geoth. Res., 166, 106-116.

Francis, P.W. and R. McAllister (1986). Volcanology from space; using Landsat thematic mapper data in the Central Andes. Eos T. Am. Geophys. Un., 67, 170-171.

Ganci, G., C. Del Negro, L. Fortuna and A. Vicari (2009). A tool for multi-platform remote sensing processing, In: Communications to SIMAI Congress, ISSN 1827-9015, 3, 281-293; doi: 10.1685/CSC09281.

Giordano, D. and D.B. Dingwell (2003). Viscosity of hydrous Etna basalt: implications for Plinian-style basaltic eruptions, B. Volcanol. 65, 8-14; doi: 10.1007/s00445-002-0233-2.

Groppelli, G. and G. Norini (2005). From geological map to volcanic hazard evaluation on Mount Etna, Italy: methodology and examples based on GIS analyses, In: J.C. 
Thouret, C. Ollier and B. Joyce (eds.), Volcanic Landforms, Processes and Hazards. Zeitschrift für Geomorphologie, 140, 167-179.

Gwinner, K., M. Coltelli, J. Flohrer, R. Jaumann, K.D. Matz, M. Marsella, T. Roatsch, F. Scholten and F. Trauthan (2006). The HRSC-AX Mt. Etna project: High-resolution orthoimages and $1 \mathrm{~m} \mathrm{DEM}$ at regional scale, In: ISPRS Commission I Symposium (Paris/Marne-la-Vallée, France, 3-6 July 2006), vol. 36, part 1, T05-23.

Harris A., S. Blake, D. Rothery and N. Stevens (1997). A chronology of the 1991 to 1993 Mount Etna eruption using advanced very high resolution radiometer data: implications for real-time thermal volcano monitoring, J. Geophys. Res., 102, 7985-8003.

Harris, A.J.L. and D.S. Stevenson (1997). Thermal observations of degassing open conduits and fumaroles at Stromboli and Vulcano using remotely sensed data. J. Volcanol. Geoth. Res., 76, 175-198.

Harris, A.J.L., L.P. Flynn, D.A. Rothery, C. Oppenheimer and S.B. Sherman (1999). Mass flux measurements at active lava lakes: implications for magma recycling, J. Geophys. Res., 104, 7117-7136.

Hérault, A., A. Vicari, A. Ciraudo and C. Del Negro (2009). Forecasting lava flow hazard during the 2006 Etna eruption: using the MAGFLOW cellular automata model, Computat. Geosci., 35, 1050-1060.

Hirn, B., C. Di Bartola, G. Laneve, E. Cadau and F. Ferrucci (2008). SEVIRI on-board Meteosat second generation, and the quantitative monitoring of effusive volcanoes in Europe and Africa, 2008 IEEE International Geoscience \& Remote Sensing Symposium (Boston, MA, July 7-11), III, 374-377.

Kaneko, T., M.J. Wooster and S. Nakada (2002). Exogenous and endogenous growth of the Unzen lava dome examined by satellite infrared image analysis, J. Volcanol. Geoth. Res., 116, 151-160.

Marti, J. and A. Felpeto (2010). Methodology for the computation of volcanic susceptibility: An example for mafic and felsic eruptions on Tenerife (Canary Islands), J. Volcanol. Geoth. Res., 195, 69-77.

Martin, A.J., K. Umeda, C.B. Connor, J.N. Weller, D. Zhao and M. Takahashi (2004). Modeling long-term volcanic hazards through Bayesian inference: an example from the Tohuku volcanic arc Japan, J. Geophys. Res., 109, B10208; doi: 10.1029/2004JB003201.

Neri, M., V. Acocella, B. Behncke, S. Giammanco, F. Mazzarini and D. Rust (2011). Structural analysis of the eruptive fissures at Mount Etna (Italy), Annals of Geophysics, 54 (5), 464-479 (this issue).

Oppenheimer, C. (1991). Lava flow cooling estimated from Landsat Thematic Mapper infrared data: the Lonquimay eruption (Chile, 1989), J. Geophys. Res., 96, 21865-21878. Pareschi, M.T., L. Cavarra, M. Favalli, F. Giannini and A.
Meriggi (2000). GIS and volcanic risk management, Nat. Hazards, 21, 361-379.

Pieri, D.C. and S.M. Baloga (1986). Eruption rate, area, and length relationships for some Hawaiian lava flows, J. Volcanol. Geoth. Res., 30, 29-45.

Pieri, D.C., L.S. Glaz and M.J. Abrams (1990). Thermal radiance observations of an active lava flow during the June 1984 eruption of Mount Etna, Geology, 18, 1018-1022.

Proietti, C., E. De Beni, M. Coltelli and S. Branca (2011). The flank eruption history of Etna (1610-2006) as a constraint on lava-flow hazard, Annals of Geophysics, 54 (5), 480490 (this issue).

Rothery, D.A., P.W. Francis and C.A. Wood (1988). Volcano monitoring using short wavelength infrared data from satellites, J. Geophys. Res., 93, 7992-8008.

Scifoni, S., M. Coltelli, M. Marsella, C. Proietti, Q. Napoleoni, A. Vicari and C. Del Negro (2010). Mitigation of lava flow invasion hazard through optimized barrier configuration aided by numerical simulation: The case of the 2001 Etna eruption, J. Volcanol. Geoth. Res., 192, 16-26.

Tramutoli, V. (2007). Robust Satellite Techniques (RST) for natural and environmental hazards monitoring and mitigation: theory and applications, Proceedings of Multitemp 2007; doi: 10.1109/ MULTITEMP.2007.4293057.

Vicari A., A. Hérault, C. Del Negro, M. Coltelli, M. Marsella and C. Proietti (2007). Modeling of the 2001 lava flow at Etna volcano by a cellular automata approach, Environm. Model. Softw., 22, 1465-1471.

Vicari, A., A. Ciraudo, C. Del Negro, A. Hérault and L. Fortuna (2009). Lava flow simulations using effusion rates from thermal infrared satellite imagery during the 2006 Etna eruption, Nat. Hazards, 50, 539-550; doi: 10.1007/s11069008-9306-7.

Wooster, M.J., B. Zhukov and D. Oertel (2003). Fire radiative energy for quantitative study of biomass burning: derivation from the BIRD experimental satellite and comparison to MODIS fire products, Remote Sens. Environ., 86, 83-107.

Wright, R., S. Blake, A. Harris and D. Rothery (2001). A simple explanation for the space-based calculation of lava eruption rates, Earth Planet. Sci. Lett, 192, 223-233.

\footnotetext{
${ }^{\star}$ Corresponding author: Annamaria Vicari,

Istituto Nazionale di Geofisica e Vulcanologia, Sezione di Catania, Osservatorio Etneo, Catania, Italy; email: annamaria.vicari@ct.ingv.it.

C 2011 by the Istituto Nazionale di Geofisica e Vulcanologia. All rights reserved.
} 